\title{
RESEARCH OF PHYSICAL AND CHEMICAL PROPERTIES OF COSMETIC EMULSIONS OF OIL IN WATER TYPE BASED ON POLYORGANOSYLOXANES AND THEIR ALTERNATIVE SUBSTITUTE
}

\author{
Oleksandra Kunik ${ }^{1,}$, Diana Saribekova1, Ludmila Saleba1, \\ Hanna Ivakhnenko', Yurij Panchenko
}

https://doi.org/10.23939/chcht13.04.526

\begin{abstract}
The paper presents the results of the study of the effects of conditioning agents on the basis of polyorganosiloxanes - cyclopentasiloxane, dimethicone, SilCare Silicone SEA, and their alternative substitute on the basis of coco caprylate Cetiol C5 on the rheological and organoleptic properties of the modeled cosmetic emulsion system. The influence of cosmetic emulsion on the basis of investigated compounds on the water-fat balance of the skin is determined. It has been established that in order to create a quality emulsion cosmetic product it is necessary to use conditioning agents on the basis of polyorganosiloxanes.
\end{abstract}

Keywords: poliorganosiloxanes, coco-caprylate, emulsion, thixotropy, water-fat balance.

\section{Introduction}

Polyorganosiloxanes are high molecular weight organ-silicon compounds [1]. The term "silicone" ("silicon-ketone") was first proposed by the English chemist F. Kipping in the early 1900's due to the similarity of the polydyphenylsiloxane and benzophenone formulas (ketone). In ketones the carbonyl group is associated with two hydrocarbon radicals; in the silicones the $\mathrm{SiO}$ group is associated with hydrocarbon radicals in the same way. Initially Kipping even used the term silicon-ketone [2]. The falsity of the name was clear from the beginning, since ketones are monomers.

The basis of current silicone chemistry nomenclature was established by A. Stock in 1916. He referred to silicone hydride compounds as silanes $\left(\mathrm{SiH}_{4}\right.$ was a monosilane). When oxygen joined two silicon atoms, the compound was referred to as a siloxane, and

\footnotetext{
${ }^{1}$ Kherson National Technical University

24, Beryslavske Hwy., 73008 Kherson, Ukraine

${ }^{2}$ Lviv Polytechnic National University,

12, Bandery St., 79013 Lviv, Ukraine

凶kulish.aleksa@gmail.com

(C) Kunik O., Saribekova D., Saleba L., Ivakhnenko H., Panchenko Yu., 2019
}

polymeric versions became known as polysiloxanes (PDMS). This system was eventually adopted by the International Union of Pure and Applied Chemistry (IUPAC). Although these descriptors are accurate and informative, they are somewhat cumbersome. Silicone chemists thus frequently use an abbreviated notation when referring to the basic groups that comprise typical silicone polymers (Table 1) [4].

Thus, in silicone shorthand notation, the<smiles>CC[Si](C)(C)O[Si](C)(C)O[Si](C)(C)O[Si](C)(C)C</smiles>

would be represented as $\mathrm{MD}_{7} \mathrm{D}_{3}{ }^{\prime} \mathrm{M}$.

This nomenclature system, while extensively employed by silicone chemists, is rarely encountered in the personal care industry. The more commonly utilized ingredient nomenclature system is that determined by the Cosmetic, Toiletry, and Fragrance Association (CTFA) or International Nomenclature for Cosmetic Ingredients (INCI). This is the system that will be employed throughout this paper. While this method of nomenclature designation is rather descriptive and detailed for most cosmetic ingredients, silicone compound identification may be somewhat complicated under this system. According to the INCI nomenclature guidelines, the same product name may be representative of numerous and sometimes quite different materials all of which conform to a similar general structure, as will be pointed out below. For this reason, extreme caution must be exercised when evaluating offset products having the same ingredient name. For example, the designation "dimethicone copolyol" may be representative of a liquid oil-in-water emulsifier with a low silicone content and low cloud point, a water-in-oil solubilizer containing a low degree of polyether modification, or a high-melting-point wax. "Dimethicone" is another example, referring to such varying materials as fluids ( $1 \mathrm{cSt}$ ), polymers (several thousands cSt), and resins characterized by very low penetration numbers, which appear to be solid under ambient conditions [5]. 
Silicone shorthand notation

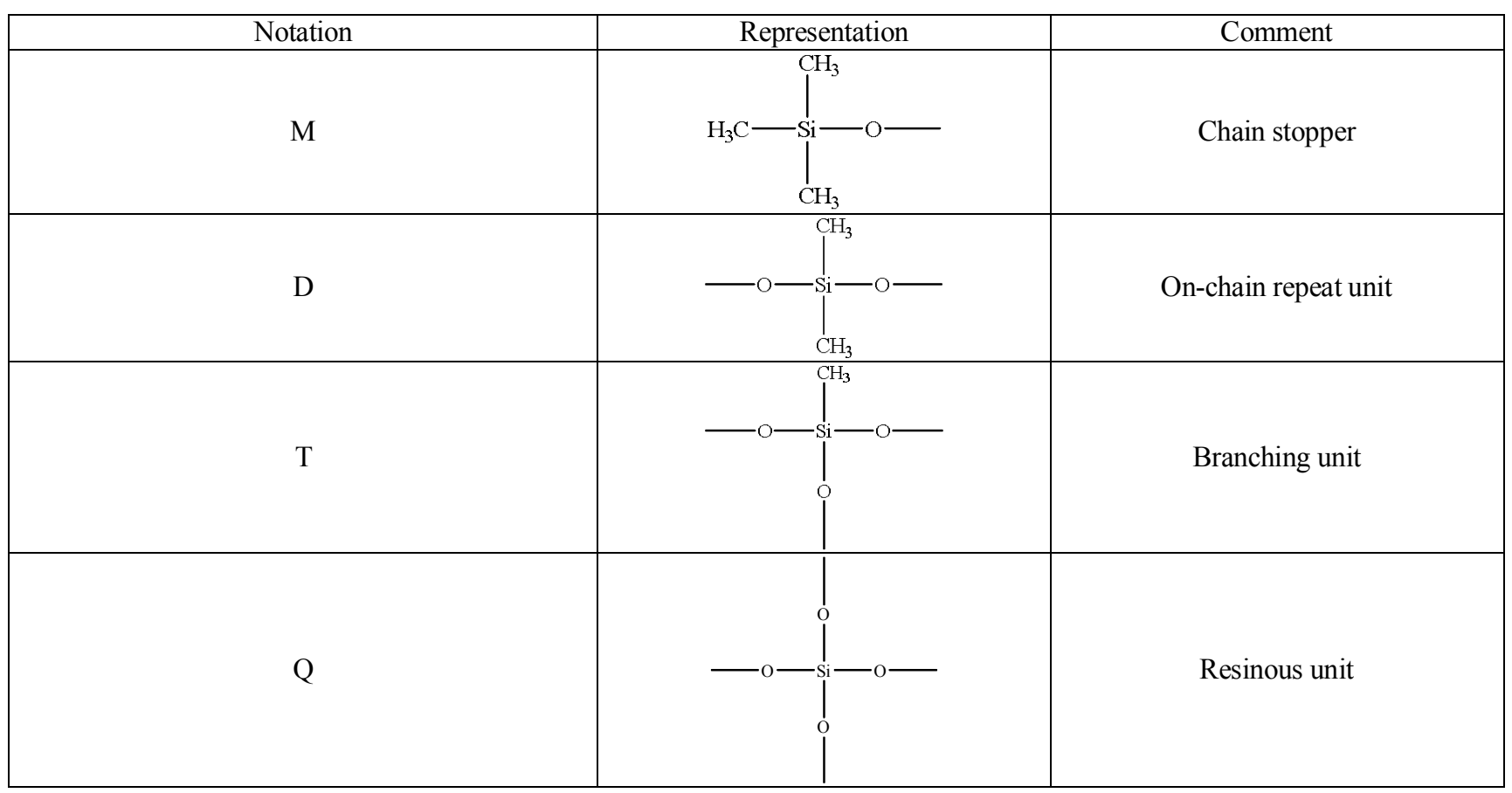

Table 2

Benefits derived from silicones in skin care formulations

\begin{tabular}{|c|c|}
\hline Material & Benefit \\
\hline Cyclomethicones & $\begin{array}{l}\text { Transient emollient, improved rub-in and spreading characteristics, carrier/diluent detackifier, } \\
\text { lubricant for valves/roller balls, improved pay-out }\end{array}$ \\
\hline Dimethicones & $\begin{array}{l}\text { Antiwhitening, antidusting, spreading agent, emollient, lubricant, improved rub-in and spreading } \\
\text { characteristics, skin protectant, water-resistant film former, lubricant for valves/roller balls }\end{array}$ \\
\hline Dimethicone copolyols & $\begin{array}{c}\text { Emulsification, foam stabilization, enhancement in formulation stability and efficacy, improved } \\
\text { skin feel }\end{array}$ \\
\hline Aminofunctional silicones & Improved feel/softness \\
\hline Phenyl-modified silicones & Shine enhancement, refractive index match, emollient, spreading agent, detackifier \\
\hline Alkyl-modified silicones & Occlusive barrier, emulsification, rheology modification, enhanced stability, water resistance \\
\hline Silicones resins & Water-resistant film formers \\
\hline Silica & Rheology modification, suspending agent \\
\hline
\end{tabular}

Note: aminofunctional silicones are considered to be skin irritants; consequently, only low-amine-content fluids or emulsions may be used in skin care applications, and only in rinse-off products such as personal cleansers.

The use of silicone materials in skin care products has been known for over 70 years, with PDMS (dimethicones) being the first commercially available silicone products offered to the cosmetic industry [4]. Nowadays, various silicones are present in almost all types of cosmetic products - care products for hair and skin, toiletries, sunscreen cosmetics and makeup products. Widespread use of silicones explains the diverse range of properties. Silicones are resistant to hydrolysis and oxidation, have no color and odor, are chemically inert, do not penetrate the skin, are an alternative replacement to fats in cosmetics, are effective at low concentrations, can create stable formula cosmetics, minimize pores and visually hide wrinkles, create opacity and other optical effects, reduce oiliness and stickiness, improve water resistance, improve uniformity of distribution of the UV filters, and are the basis of a huge variety of textures with sensory properties that can not be obtained with any other ingredients (Table 2).

The modern ranges of some of the most common silicones for cosmetic purposes are given in Table 3 . 
The modern ranges of the silicones for cosmetic purposes

\begin{tabular}{|c|c|c|}
\hline The manufacturer & Trading name & INCI \\
\hline Clariant AG, Switzerland & SilCare Silicone SEA & Trideceth-9 PG-Amodimethicone (and) Trideceth-12 \\
\hline \multirow{3}{*}{$\begin{array}{c}\text { Chemsil Silicones, Inc., } \\
\text { USA }\end{array}$} & Cosmetic fluid 4120-DM & Cyclopentasiloxane (and) Polysilicone-22 \\
\cline { 2 - 3 } & Cosmetic fluid 8100-OH & Trisiloxane (and) Dimethicone (and) Dimethiconol \\
\cline { 2 - 3 } & Cosmetic fluid 6570-DM & Disiloxane (and) Cyclopentasiloxane (and) Dimethicone \\
\cline { 2 - 3 } Dow Corning, USA & Emulsil S-399 & Lauryl PEG-9 Polydimethylsiloxyethyl Dimethicone \\
\cline { 2 - 3 } & DC 9011 & Cyclopentasiloxane (and) PEG-12 Dimethicone Cross-Polymer \\
\cline { 2 - 3 } & ES 5612 & PEG-10 Dimethicone \\
\cline { 2 - 3 } & FZ 3196 & Caprylyl Methicone \\
\cline { 2 - 3 } Elkem, Norway & DC 2-2078 556 Carbinol Fluid & Aminopropyl Phenyl Trimethicone \\
\cline { 2 - 3 } & Mirasil DM 5000 & Bis-Hydroxyethoxypropyl Dimethicone \\
\cline { 2 - 3 } & Mirasil ADMH-E 125 & Dimethicone \\
\cline { 2 - 3 } & Mirasil PTM & Pater (and) Propoxytetramethylpiperidinyl Dimethicone (and) \\
\cline { 2 - 3 } & Mirasil C-DML & Prideceth-6 \\
\hline Brenntag, Germany & BRB CM 50 & Cyclopenenthicone \\
\hline $\begin{array}{c}\text { BRB International BV } \\
\text { Netherlands }\end{array}$ & BRB Silicone Oil 350 cSt & Dimethicone \\
\hline
\end{tabular}

Despite the natural origin of silicones, the final product is not natural because it undergoes chemical treatment before being used as a cosmetic ingredient. Therefore, cosmetic brands that create eco-cosmetics (Ecocert, Cosmebio, BDIH, ICEA, NaTrue and others) reject silicones in cosmetics, finding them an alternative replacement $-\mathrm{a}$ mixture of vegetable oils and organic wax.

Also, in connection with the triumph of chemophobia among consumers of cosmetics, there is a misconception that silicones are at least undesirable and, as a maximum, they are dangerous, and their use should be avoided [6,7]. This, incidentally, is well used by marketing companies placing cosmetic products on the label tag "silicone free" and absolutely without specifying how harmful may a not fully tested substitute be. Nevertheless, according to Report from the Commission to the European Parliament and the Council on Product Claims made on the basis of common criteria in the field of cosmetics (19.09.2016), the use of such techniques is unfair to consumers and competitors, as it destroys consumer's confidence in the safety assessment procedures and creates an advantage where there is really no real benefit [8]. Indeed, according to CIR (Cosmetic Ingredient Review), supported by dozens of detailed studies, silicones are recognized as non-toxic and noncancerogenic, they do not cause sensitization and genetic disorders, do not accumulate in the body and even when applied in industry they do not pose a risk to workers either in terms of acute reactions, or in relation to the risk of occupational diseases [9].
The purpose of this work was to determine the physico-chemical properties of cosmetic emulsions of oil in water type based on polyorganosyloxanes and their alternative substitutes that act as conditioning agents for the skin.

\section{Experimental}

The following poliorganosiloxanes were selected for the study: cyclopentasiloxane (Brenntag, Germany), dimethicone (BRB International BV, the Netherlands), SilCare Silicone SEA (Clariant, Switzerland) and their alternate substitute Cetiol C5 (BASF SE, Germany). Their characteristics are presented in Table 4.

The properties of silicones were investigated in the modeled system emulsion containing fat phase of $50 \%$. As the main fat component mineral oil was selected due to its inertia. As an emulsifier Eumulgin ${ }^{\circledR}$ Prisma was selected, as an auxiliary emulsifier (co-emulsifier) cetearyl alcohol was selected (Table 5).

To prepare the simulated emulsion, mineral oil, cetearyl alcohol and Eumulgin ${ }^{\circledR}$ Prisma were heated in a glass in a water bath at $333.15 \mathrm{~K}$. In parallel the second cup in a water bath calculated amount of distilled water was heated to the same temperature $(333.15 \mathrm{~K})$. At highspeed stirring an emulsion was created by gradually adding a hot water phase. In the process of emulsification the temperature of the mixture was periodically measured. After cooling the emulsion to $323.15 \mathrm{~K}$ conditioning components were added. 
Table 4

Characteristics of the studied conditioning agents

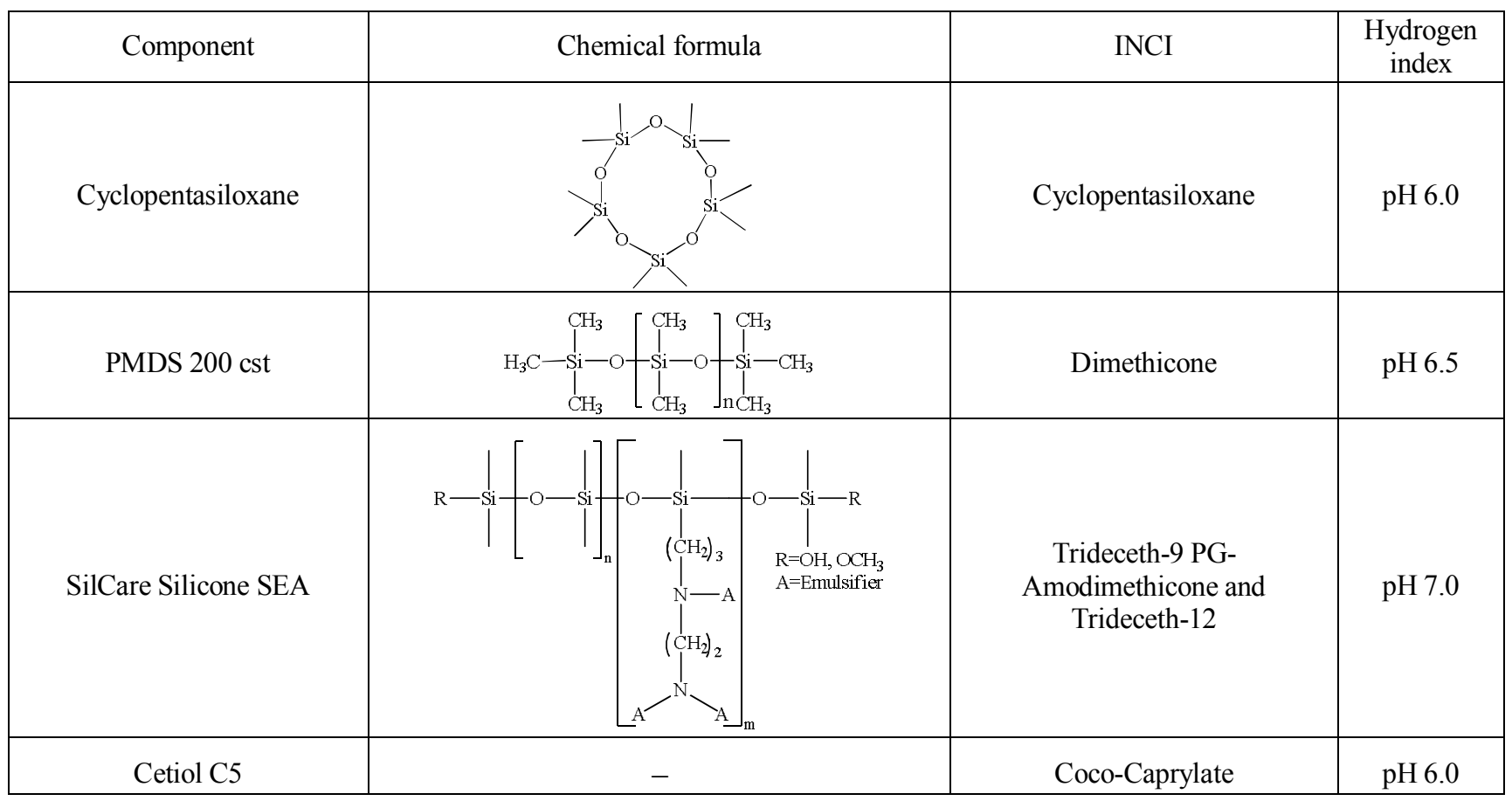

Table 5

Characteristics of cosmetic emulsion components

\begin{tabular}{|c|c|c|}
\hline Component & INCI & Weight fraction \\
\hline Mineral Oil & Paraffinum Liquidum (EU) / Mineral Oil & 50.0 \\
\hline Eumulgin ${ }^{\circledR}$ Prisma (BASF SE, Germany) & Disodium Cetearyl Sulfosuccinate & 0.7 \\
\hline Cetearyl Alcohol & Cetearyl Alcohol & 4.0 \\
\hline Distilled water & Distilled Water & 45.3 \\
\hline
\end{tabular}

Colloidal and thermal stability and $\mathrm{pH}$ of the resulting emulsion was determined according to [10].

In order to evaluate the rheological properties of the cosmetic emulsion, the determination of the viscosity dependence on the shear rate and the dependence of the applied shear stress on the rate of displacement of the studied samples of the cream was performed on the "Reotest-2" rotary viscometer. formula:

Tensile displacement was determined by the

$$
\tau_{r}=z \alpha
$$

where $\tau_{r}$ is the shear stress, $\mathrm{Pa} ; z$ is a constant of a cylinder, $\mathrm{Pa} / \mathrm{scale}$ divisions; $\alpha$ is a value of the scale on the indicator device, scale divisions.

Dynamic viscosity was determined by the formula:

$$
\eta=\frac{\tau}{D_{r}}
$$

where $\eta$ is the dynamic viscosity, $\mathrm{Pa} \cdot \mathrm{s}$; $\tau_{r}$ is the shear stress, $\mathrm{Pa} ; D_{r}$ is the shear rate, $\mathrm{s}^{-1}$ (tabulated value).

The degree of thixotropic restoration of viscosity was determined by the formula:

$$
S=\frac{1}{n} \sum_{1}^{n}\left(\frac{\eta_{1 i}}{\eta_{0 i}}\right) 100
$$

where $\mathrm{S}$ is the degree of thixotropic restoration of viscosity, $\% ; n$ is a number of fixed values of the gradient of the shear rate; $\eta_{1 i}$ is a viscosity at $i$-th rate of displacement, measurement in the mode of downward gradient of shear rate, $\mathrm{Pa} \cdot \mathrm{s} ; \eta_{0 i}$ is a viscosity at i-th shear rate, measurement in the mode of increasing gradient of shear rate, $\mathrm{Pa} \cdot \mathrm{s}$.

The amount of moisture and fat on the skin was determined using a tester with a digital high-sensitivity Skin Detector SG-5E. 
Influence of the concentration of conditioning agents on the physical and chemical parameters of the cosmetic emulsion

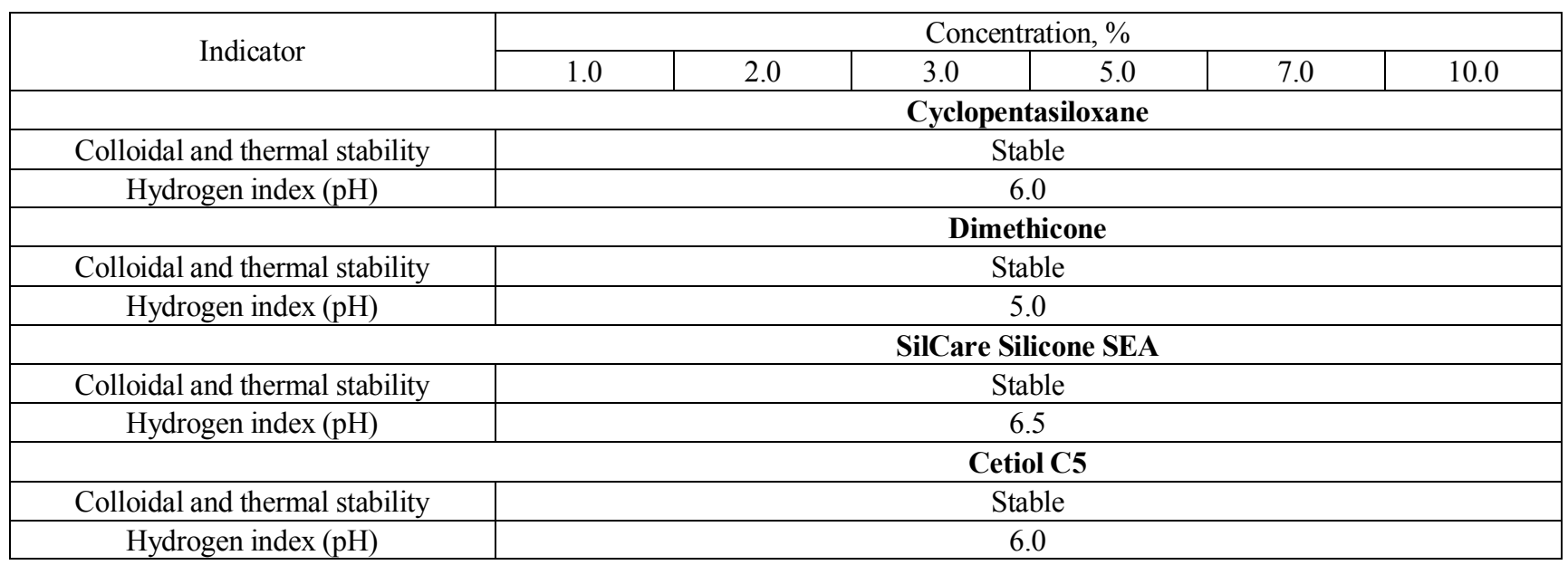

\section{Results and Discussion}

In the first stage of the work the determination of the influence of the concentration of the studied conditioning agents on the basic parameters of the simulated cosmetic emulsion was carried out, the results are presented in Table 6.The obtained data (Table 6) show that samples of a cosmetic emulsion with the addition of the investigated compounds at concentrations from 1 to $10 \%$ meet the requirements [10], since they are colloidal and thermo-stable, $\mathrm{pH}$ being within the permitted range of 5.0-6.5.

Influence of conditioning agents on the rheological properties of the obtained simulated emulsion is presented in Fig. 1. It should be noted that for the image of the viscosity and applied voltage dependence on the shear rate the natural logarithm scale was used since the data in the natural scale has a difference in values of several orders of magnitude.

The analysis of rheological studies (Fig.) shows that in the logarithmic scale of measurement with increasing rate of displacement; the initial structure of the emulsion collapses, the molecules are actively moving one relative to one, decreasing the viscosity index and increasing the shear stress. It should be noted that the rheological properties are practically immaterial at adding of cyclopentasiloxane, dimethicone and Cetiol C5 (except for the concentration of $1 \%$ at maximum shear rates) to the emulsion. The exception is SilCare Silicone SEA, which in the investigated range of concentrations (1$10 \%$ ) causes a significant dilution of the cosmetic emulsion. The rheological behavior of the fluid includes thixotropic properties - the ability of the system to return for a certain time to the initial viscosity after removal of the voltage. This phenomenon is associated with the kinetics of destruction (at voltage) and the restoration (when removing the voltage) of intermolecular bonds in a liquid system [12]. The calculation of the degree of thixotropic viscosity recovery (Table 7) was carried out based on the graphs of dynamic viscosity dependence on shear rate gradient in direct and reverse course.

According to the data (Table 7) the highest degree of thixotropic restoration of viscosity has an emulsion with the addition of cyclopentasiloxane. Sufficiently unstable indicators of thixotropy are typical of emulsion samples from SilCare Silicone SEA. It should be noted that adding of conditioning additives to the cosmetic emulsion significantly increases the degree of thixotropic restoration of viscosity - from $56.6 \%$ (base sample) to $115.1 \%$ (SilCare Silicone SEA at a concentration of $7 \%$ ).

Investigations of the dependence of the amount of moisture and fat on the skin on the concentration of conditioning additives (measurement before applying the emulsion and after 1, 2, 3 and $4 \mathrm{~h}$ after application) are presented in Tables 8-11.

According to the data presented in Tables 8-11, the basic sample of a cosmetic emulsion when applied to the skin causes an imbalance of moisture and fat content - the moisture is insufficient $(\max 29.6 \%)$ and the excess fat ( $\min 40.5 \%$ ). Adding of polyorganosiloxanes to the cosmetic emulsion significantly increases the moisture content of the skin $(\max 45.9 \%)$ and reduces its fat content (min $23.3 \%$ ). In the individual concentrations of 

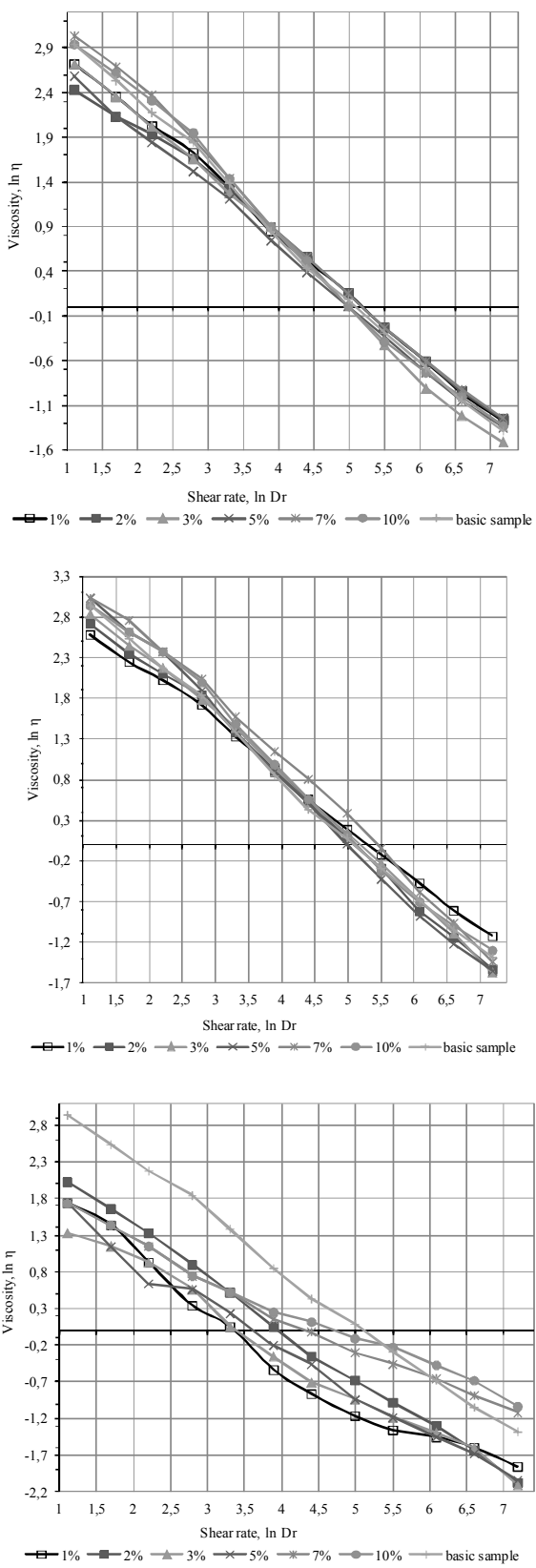

c) SilCare Silicone SEA

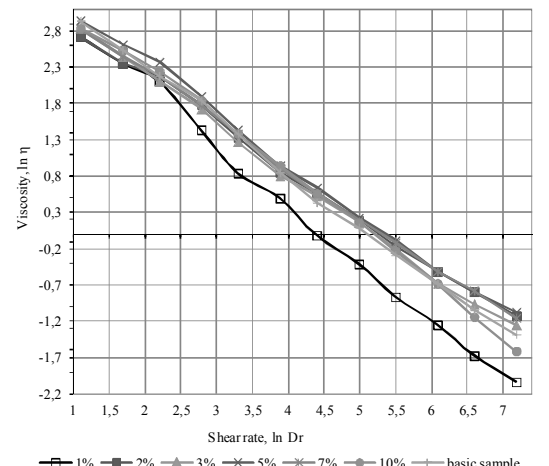

d) Cetiol C5

b) dimethicone

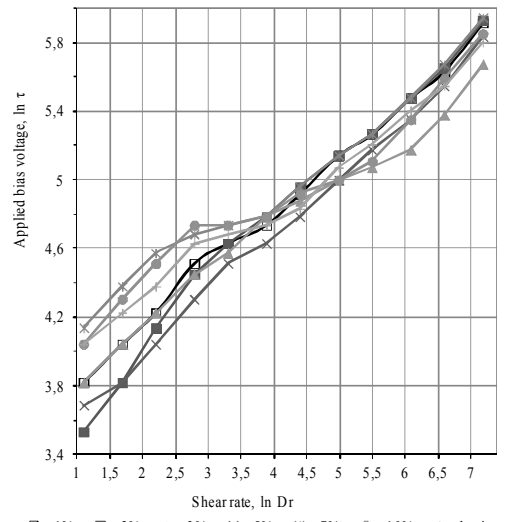

a) cyclopentasiloxane
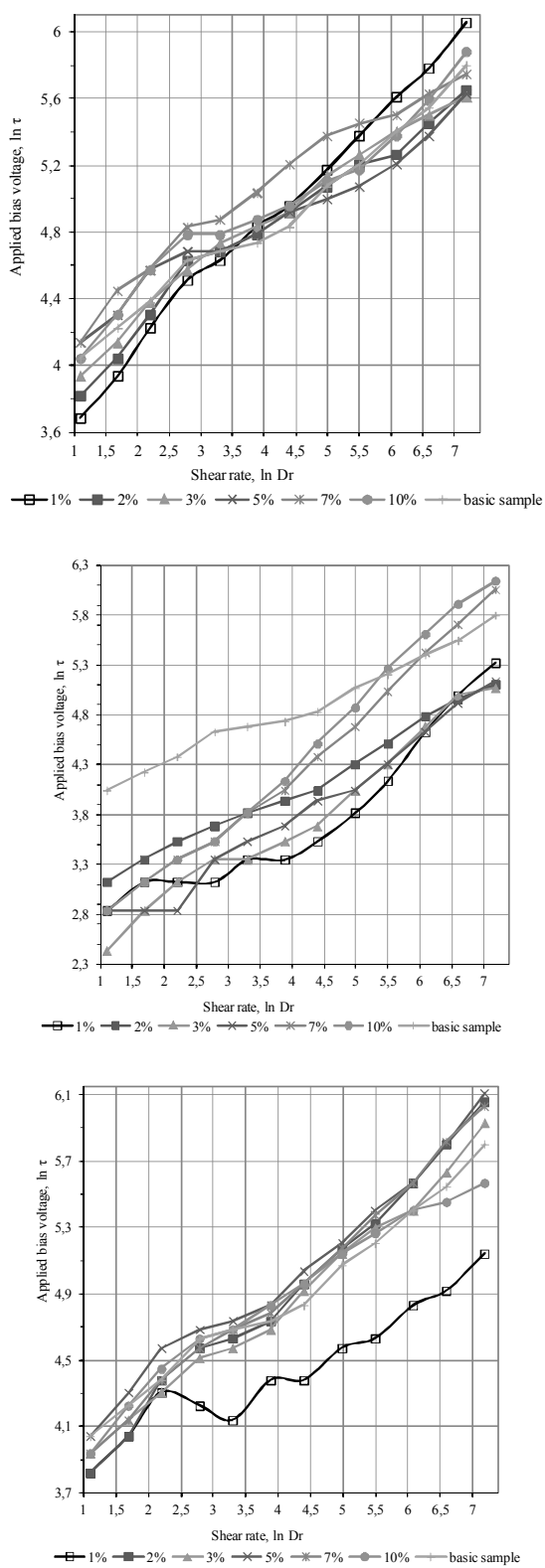

$\longrightarrow 1 \%-2 \%-3 \% \div 5 \%-7 \%-10 \%-$ basic samp

Fig. Influence of concentration of conditioning agents on rheological properties of cosmetic emulsion 
The degree of thixotropic restoration of viscosity, \%

\begin{tabular}{|c|c|c|c|c|c|c|c|}
\hline \multirow{2}{*}{ Component } & \multicolumn{7}{|c|}{ Concentration, $\%$} \\
\hline & 0.0 & 1.0 & 2.0 & 3.0 & 5.0 & 7.0 & 10.0 \\
\hline Cyclopentasiloxane & \multirow{4}{*}{56.6} & 93.9 & 84.0 & 83.0 & 95.3 & 89.9 & 85.2 \\
\hline Dimethicone & & 95.8 & 73.1 & 84.6 & 75.4 & 80.4 & 83.9 \\
\hline SilCare Silicone SEA & & 74.9 & 49.3 & 64.2 & 57.1 & 115.1 & 99.9 \\
\hline Cetiol C5 & & 70.5 & 89.7 & 89.5 & 95.5 & 98.3 & 70.1 \\
\hline
\end{tabular}

Table 8

Dependence of the amount of moisture and fat

on the skin on concentration of cyclopentasiloxane, $\%$

\begin{tabular}{|c|c|c|c|c|c|c|c|c|c|c|c|c|c|c|}
\hline \multirow{3}{*}{$\begin{array}{c}\text { Time, } \\
\mathrm{h}\end{array}$} & \multicolumn{14}{|c|}{ Concentration, \% } \\
\hline & \multicolumn{2}{|c|}{0} & \multicolumn{2}{|c|}{1.0} & \multicolumn{2}{|c|}{2.0} & \multicolumn{2}{|c|}{3.0} & \multicolumn{2}{|c|}{5.0} & \multicolumn{2}{|c|}{7.0} & \multicolumn{2}{|c|}{10.0} \\
\hline & $m$ & $f$ & $m$ & $f$ & $m$ & $f$ & $m$ & $f$ & $m$ & $f$ & $m$ & $f$ & $m$ & $f$ \\
\hline 0 & 27.8 & 41.7 & 30.1 & 45.1 & 27.4 & 41.0 & 26.4 & 39.6 & 28.5 & 42.7 & 28.8 & 43.1 & 29.8 & 44.7 \\
\hline 1 & 27.9 & 41.9 & 43.3 & 31.0 & 45.9 & 31.2 & 37.3 & 24.9 & 30.9 & 46.4 & 31.2 & 37.1 & 30.3 & 45.4 \\
\hline 2 & 26.8 & 40.5 & 32.8 & 49.2 & 34.8 & 32.2 & 30.7 & 45.9 & 33.4 & 24.8 & 29.6 & 44.4 & 30.4 & 45.6 \\
\hline 3 & 26.8 & 40.6 & 35.8 & 23.9 & 34.8 & 32.6 & 30.9 & 46.2 & 33.4 & 32.4 & 30.2 & 45.7 & 34.2 & 32.8 \\
\hline 4 & 29.6 & 44.3 & 35.3 & 32.8 & 37.2 & 34.0 & 31.1 & 46.6 & 33.5 & 40.6 & 31.1 & 46.7 & 36.3 & 33.5 \\
\hline
\end{tabular}

Table 9

Dependence of the amount of moisture

and fat on the skin on concentration of dimethicone, $\%$

\begin{tabular}{|c|c|c|c|c|c|c|c|c|c|c|c|c|c|c|}
\hline \multirow{3}{*}{$\begin{array}{c}\text { Time, } \\
\mathrm{h}\end{array}$} & \multicolumn{14}{|c|}{ Concentration, \% } \\
\hline & \multicolumn{2}{|c|}{0} & \multicolumn{2}{|c|}{1.0} & \multicolumn{2}{|c|}{2.0} & \multicolumn{2}{|c|}{3.0} & \multicolumn{2}{|c|}{5.0} & \multicolumn{2}{|c|}{7.0} & \multicolumn{2}{|c|}{10.0} \\
\hline & $m$ & $f$ & $m$ & $f$ & $m$ & $f$ & $m$ & $f$ & $m$ & $f$ & $m$ & $f$ & $m$ & $f$ \\
\hline 0 & 27.8 & 41.7 & 27.7 & 41.6 & 33.4 & 40.3 & 36.4 & 43.6 & 30.1 & 45.2 & 30.6 & 45.7 & 29.1 & 24.3 \\
\hline 1 & 27.9 & 41.9 & 26.2 & 39.3 & 31.3 & 46.9 & 35.3 & 38.2 & 28.9 & 43.4 & 28.7 & 43.4 & 25.5 & 32.7 \\
\hline 2 & 26.8 & 40.5 & 28.3 & 42.4 & 33.7 & 24.9 & 39.7 & 43.7 & 30.6 & 45.9 & 30.8 & 46.1 & 29.2 & 26.6 \\
\hline 3 & 26.8 & 40.6 & 29.5 & 44.3 & 34.9 & 25.0 & 38.2 & 44.2 & 31.7 & 31.1 & 32.5 & 30.2 & 40.5 & 27.4 \\
\hline 4 & 29.6 & 44.3 & 30.7 & 46.1 & 37.5 & 25.1 & 36.7 & 46.0 & 34.5 & 32.4 & 34.0 & 31.8 & 41.9 & 28.0 \\
\hline
\end{tabular}

Table 10

Dependence of the amount of moisture

and fat on the skin on concentration of SilCare Silicone SEA, \%

\begin{tabular}{|c|c|c|c|c|c|c|c|c|c|c|c|c|c|c|}
\hline \multirow{3}{*}{$\begin{array}{c}\text { Time, } \\
\mathrm{h}\end{array}$} & \multicolumn{14}{|c|}{ Concentration, $\%$} \\
\hline & \multicolumn{2}{|c|}{0} & \multicolumn{2}{|c|}{1.0} & \multicolumn{2}{|c|}{2.0} & \multicolumn{2}{|c|}{3.0} & \multicolumn{2}{|c|}{5.0} & \multicolumn{2}{|c|}{7.0} & \multicolumn{2}{|c|}{10.0} \\
\hline & $m$ & $f$ & $m$ & $f$ & $m$ & $f$ & $m$ & $f$ & $m$ & $f$ & $m$ & $f$ & $m$ & $f$ \\
\hline 0 & 27.8 & 41.7 & 27.2 & 40.7 & 28.4 & 40.7 & 28.7 & 43.0 & 32.9 & 49.3 & 34.7 & 32.1 & 28.3 & 42.1 \\
\hline 1 & 27.9 & 41.9 & 29.4 & 44.1 & 35.2 & 40.4 & 28.7 & 43.0 & 34.9 & 23.3 & 38.5 & 25.8 & 30.4 & 45.6 \\
\hline 2 & 26.8 & 40.5 & 32.4 & 49.0 & 36.3 & 33.5 & 30.1 & 45.1 & 34.7 & 32.3 & 38.6 & 25.8 & 34.7 & 49.1 \\
\hline 3 & 26.8 & 40.6 & 32.6 & 49.1 & 36.5 & 33.6 & 30.1 & 45.1 & 34.7 & 32.3 & 38.7 & 25.9 & 33.3 & 48.9 \\
\hline 4 & 29.6 & 44.3 & 32.7 & 49.1 & 36.7 & 33.7 & 30.1 & 45.2 & 36.5 & 24.4 & 41.5 & 27.7 & 32.4 & 48.5 \\
\hline
\end{tabular}


Table 11

Dependence of the amount of moisture and fat on the skin on concentration of Cetiol C5, \%

\begin{tabular}{|c|c|c|c|c|c|c|c|c|c|c|c|c|c|c|}
\hline \multirow{3}{*}{$\begin{array}{l}\text { Time, } \\
\text { hours }\end{array}$} & \multicolumn{14}{|c|}{ Concentration, $\%$} \\
\hline & \multicolumn{2}{|c|}{0} & \multicolumn{2}{|c|}{1.0} & \multicolumn{2}{|c|}{2.0} & \multicolumn{2}{|c|}{3.0} & \multicolumn{2}{|c|}{5.0} & \multicolumn{2}{|c|}{7.0} & \multicolumn{2}{|c|}{10.0} \\
\hline & $m$ & $f$ & $m$ & $f$ & $m$ & $f$ & $m$ & $f$ & $m$ & $f$ & $m$ & $f$ & $m$ & $f$ \\
\hline 0 & 27.8 & 41.7 & 25.3 & 38.0 & 26.6 & 40.1 & 29.2 & 43.8 & 30.0 & 45.1 & 26.7 & 40.1 & 27.1 & 40.6 \\
\hline 1 & 27.9 & 41.9 & 28.4 & 42.5 & 29.6 & 44.3 & 28.8 & 43.2 & 27.9 & 41.8 & 28.8 & 43.2 & 25.6 & 37.6 \\
\hline 2 & 26.8 & 40.5 & 31.0 & 46.5 & 29.6 & 44.4 & 34.8 & 46.2 & 33.0 & 49.5 & 30.8 & 46.1 & 30.3 & 45.4 \\
\hline 3 & 26.8 & 40.6 & 31.4 & 47.2 & 30.2 & 45.7 & 37.8 & 46.2 & 33.3 & 45.2 & 31.1 & 45.3 & 30.8 & 46.1 \\
\hline 4 & 29.6 & 44.3 & 32.5 & 48.7 & 30.8 & 46.2 & 40.1 & 46.3 & 33.6 & 41.0 & 32.2 & 48.2 & 31.0 & 46.4 \\
\hline
\end{tabular}

Notes for Tables 8-11: $m$ is an amount of moisture, $\% ; f$ is an amount of fat, $\%$; the light-gray color of the water-fat balance of the skin is marked, everything else (no color) - an imbalance.

the compounds studied a balance of moisture and fat on the skin is achieved. An alternative substitute silicone Cetiol C5 showed the worst performance of water-lipid balance. It should be noted that the minimum amount of fat in the skin in the application of conditioning additives is $37.6 \%$ as opposed to $23.3 \%$ using polyorganosiloxanes. The obtained results confirm the impossibility of competing coco-caprylate of natural origin Cetiol C5 with polyorganosiloxanes of synthetic origin.

Further research will focus on determining the effects of the studied conditioning agents on the organoleptic characteristics of the simulated cosmetic emulsion.

\section{Conclusions}

The emulsion system consisting of mineral oil as well as main and auxiliary emulsifiers was simulated to study the physico-chemical properties of polyorganosiloxanes and their alternate substitutes. It has been established that samples of cosmetic emulsion with the addition of cyclopentasiloxane, dimethicone, SilCare Silicone SEA and Cetiol C5 at the concentration of 1$10 \%$ are colloidal- and thermo-stable; $\mathrm{pH}$ is within the range of 5.0-6.5. It was found that cyclopentasiloxane, dimethicone and Cetiol C5 in concentrations of $1-10 \%$ practically do not change the viscosity of the emulsion. SilCare Silicone SEA causes slight dilution. The highest degree of thixotropic viscosity recovery is characteristic for an emulsion with the addition of cyclopentasiloxane, indicating its high stability.

On the basis of the study of the water-fat balance of the skin it was determined that the addition of polyorganosiloxane to the cosmetic emulsion significantly increases skin moisture $(\max 45.9 \%$ ) and decreases its fat content $(\min 23.3 \%$ ); the moisture and fat balance is achieved in separate concentrations of the investigated compounds. The use of polyorganosiloxanes of synthetic origin is necessary for the creation of a qualitative emulsion cosmetic agent; not all conditioning agents of natural origin can act as their valuable substitutes. The results obtained can be used as a basis for improving the formulations of such emulsion cosmetics of water in oil type as protective, cold and creams of atopic skin care creams.

\section{References}

[1] Auner N., Weis J. (Eds.): Organosilicon Chemistry I. From Molecules to Materials. WILEY-VCH Verlag GmbH, Weinheim 1994. [2] Rochow E.: An Introduction to the Chemistry of the Silicones. John Wiley \& Sons, Inc. 1947.

[3] Brook M.: Silicon in Organic, Organometallic, and Polymer Chemistry. Wiley, New York 2000.

[4] Goddard D., Gruber J.: Principles of Polymer Science and Technology in Cosmetics and Personal Care. Marcel Dekker AG, New York 1999.

[5] Rejchsfeld V.: Kremniyorhanycheskie Soedynenia i Materialy na ikh Osnove. Nauka, Leningrad 1984.

[6] http://www.marieclaire.ru/krasota/7-sereznyih-prichin-izbegatsilikonyi-v-kosmetike/

[7] https://butik.cutrin.com.ua/chem-opasny-silikony-v-kosmetikedlya-volos

[8] http://eur-lex.europa.eu/legal-

content/EN/TXT/?uri=CELEX:52016DC0580

[9] https://www.cir-safety.org/ingredients

[10] Ribeiro R., Barreto S., Ostrosky E. et al.: Molecules, 2015, 20,

2492. https://doi.org/10.3390/molecules20022492

[11] Saribiekova D., Kunyk O., Salieba L. et al.: Naukovi Visti

NTUU «KPI», 2016, 6, 107.

[12] http://morfo.phyche.ac.ru/Research_methods/Rheology/print_html

Received: May 03, 2018 / Revised: June 27, 2018 / Accepted: September 2018 


\section{ДОСЛІДЖЕННЯ ФІЗИКО-ХІМІЧНИХ ВЛАСТИВОСТЕЙ КОСМЕТИЧНИХ ЕМУЛЬСІЙ ТИПУ ВОДА В ОЛІЇ НА ОСНОВІ ПОЛІОРГАНОСИЛОКСАНІВ ТА ЇХ АЛЬТЕРНАТИВНИХ ЗАМІННИКІВ}

Анотація. Досліджено вплив кондиціонуючих агентів на основі поліорганосилоксанів - циклопентасилоксану, диметикону, SilCare Silicone SEA ma їх альтернативного за- мінника на основі коко-каприлату Cetiol C5 на реологічні та органолептичні властивості змодельованої косметичної емульсійної системи. Визначено вплив складу косметичної емульсії на основі досліджуваних сполук на водно-жировий баланс шкіри. Встановлено, щуо для створення якісного емульсійного косметичного засобу необхідне застосування кондиціонуючих агентів на основі поліорганосилоксанів.

Ключові слова: поліорганосилоксани, коко-каприлат, емульсія, тиксотропність, водно-жсиовий баланс. 